\title{
Experimental Investigation of a Two- Dimensional Shock-Turbulent Boundary Layer interaction with Bleed
}

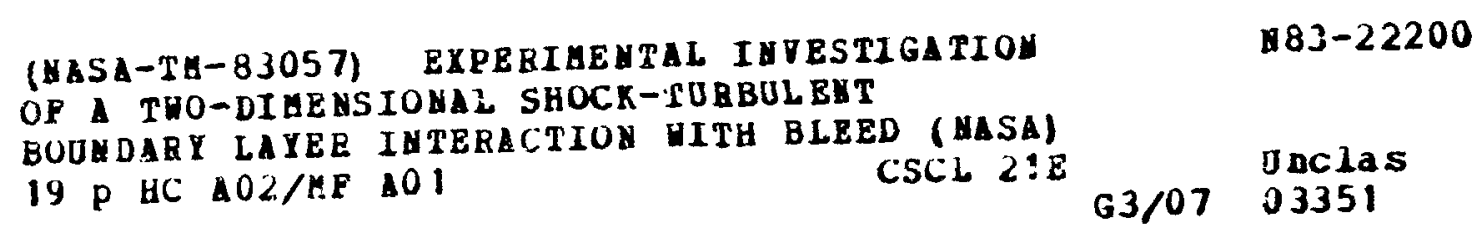

W. R. Hingst and F. T. Tanji

Lewis Research Center

Cleveland, Ohio

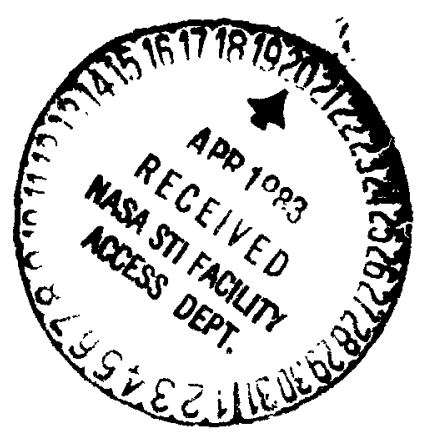

Prepared for the

Twenty-First Aerospace Sciences Conference sponsored by the American Institute of Aeronautics and Astronautics

Reno, Nevada, January 10-13, 1983 


\title{
EXPERIMENTAL INVESTIGATION OF A TWO-DIMENSIONAL SHOCK-TURBULENT BOUNDARY LAYER INTERACTION WITH BLEED
}

\author{
W.R. Hingst and F.T. Tanji
}

National Aeronautics and Space Administration

Lewis Research Center

Cleveland, Ohio 44135

\begin{abstract}
The two-dimensional interaction of an oblique shock wave with a turbulent boundary layer that included the effect of bleed was examined experimentally using a shock generator mounted across a supersonic wind tunnel. The studies were performed at Mach numbers 2.5 and 2.0 and unit Reynolds number of approximately $2.0 \times 10$ /meter. The study includes surface oil flow visualization, wall staiic pressure distributions and boundary layer pitot pressure pro-

$\approx$ fi.es. In addition, the variation of the local bleed rates were measured.

N The results show the effect of the bleed on the boundary layer as well as the

$\vec{i}$ effect of the flow conditions on the local bleed rate.
\end{abstract}

\section{NOMENCLATURE}

B location of bleed resion boundary

$M$ mach number

$N$ bleed row number

$\mathrm{P}$ pressure, $\mathrm{kPa}$

PT pitot pressure, $\mathrm{kPa}$

Re unit Reynolds number, $\mathrm{m}^{-1}$

$T$ temperature, ${ }^{\circ} \mathrm{K}$

$\checkmark$ velocity, $\mathrm{m} / \mathrm{sec}$

w mass flow rate per bleed row, $\mathrm{kg} / \mathrm{sec}$

W tctál mass flow rate, $\mathrm{kg} / \mathrm{sec}$

$X$ distance

$x_{s}$ coordinate from $x_{0}$ to leading edge of shock generator, $\mathrm{cm}$

$\bar{x} \quad$ nond iriensionalized distan_e $x-x_{0} / \delta_{0}$

$y$ distance normal to wall surface

$y_{s}$ courrinite from wall surface to leading edge of shock generators, cm

$\delta$ bcurdar. iayer thickness, cin

$\theta \quad$ shock generator angle, degroos

o density, $\mathrm{kg} / \mathrm{m}^{3}$ 


\title{
Subscripts
}

\author{
t stagnatior conditions \\ - conditions at initial profile \\ p bleed plenum conditions \\ w wall conditions
}

\section{INTRODUCTION}

One of the more interesting problems in fluid mechanics is the interac$t$ ion of a shock wave with a turbulent boundary layer. The high speed flow, the large pressure gradients and high shear stresses combine to make this problem a challenge to the experimentalist as well as to the specialist in analytical techniques. Recent developments in computational fluid dynamics have provided the opportunity to calculate these interactions. However, in many cases data is not available in sufficient detail to verify the accuracy of the computational methods. The study of two-dimensional interactions, while not always easy to obtain experimentally, provides a simplification that is useful in the verification of the computational methods. For shock waves of sufficient strength, separated flow will occur in the interaction region. In applications where shock-boundary layer interactions occur, these flow separations may have a detrimental effect on the performance of aerodynamic components. To prevent this, various boundary control techniques have been devised, see Reference 1. One of these techniques, which has been applied extensively for internal flow situations such as supersonic in?ets, is boundary layer bleed.

The interaction of a shock wave with a turbulent boundary layer has been investigated previously in a number of studies. For rectangular test geometry References 2 and 3 are typical examples of these investigations. On the other hand, Reference 4 is an investigation conducted in axisymmetric test geometry. Substantially fewer studies are available that include bleed in the interaction region. The investigation of the shock wave-boundary layer interaction with bleed in an axisymmetric geometry is reported in Reference 5 . In addition, Reference 6 is a study of similar interactions in an axisymmetric supersonic inlet. To verify computational methods that include the effects of boundary layer bleed, the experimental investigation should include a measure of the local bleed rates, since this information is needed as a boundary condition for the computations. That is, information on how the bleed rate varies through the interaction region is needed in addition to the total bleed. However, detailed information on the local bleed rates has not been available. The present experimental work was designed to extend the data base of two-dimensional oblique shock-boundary layer interactions with b?eed. The investigation was motivated by two needs. The first is to obtain data to verify computational methods, and the second is to provide information needed to analytically model the bleed process. This modeling is necessary in using the computational inethods for design purposes because the bleed rates in general will not be known apriori. The bleed rate is a function of the flow properties. Detailed boundary layer profiles were made both upstream and through the interaction region. Corresponding wall static pressure measurements were 
also recorded. The boundary layer bleed was removed through discrete bleed holes and exhausted through a separate bleed system. Since the motivation of the study was to provide data for verification of computational methods, local bleed rates were included in the study. This variation in the bleed rate through the interaction region was measured with hot wire probes located in the bleed plenum. Flow visualization techniques were also employed. These were used primarily to check for the two-dimensionality of the flow. The tests were conducted in a supersonic wind tunnel with a nominally square cross section, using the naturally occurring boundary layers on the tunnel walls. The flow Mach numbers for the tests were nominally 2.0 and 2.5. The unit Reygolds numbers based on free stream conditions were approximately $2.0 \times 10^{2} /$ meter. Shock generator angles were varied from $2.5^{\circ}$ to $8.0^{\circ}$.

\section{APPARATUS AND TEST PROCEDURE}

Wind Tunnel

The investigation was conducted in the Lewis $1 \times 1$ Supersonic Wind Tunnel. This tunnel, which has a test section of $30.5 \mathrm{~cm}$ by $31.0 \mathrm{~cm}$, is continuous running and has separate filtered high pressure supply and exhaust systems. The Mach number can be varied from 1.6 to 4.0 in increments by selecting from interchangeable nozzles. A separate bleed exhaust system was installed for this boundary layer bleed test. This system included a mechanical boost pump that allowed the pressure in the tunnel bleed plenum to be reduced below that available from the tunnel exhaust system.

Experimental Model

The experimental model used in this study is shown schematically in Figure 1. A shock generator was mounted to span the tunnel. The shock generator was capable of being pitched to allow oblique shock waves of varying strengths to be produced. The shock wave interacts with the naturally occurring turbulent boundary layer on the tunnel wall. To provide uniform twodimensional flow, boundary layer fences were installed that resulted in a $12.7 \mathrm{~cm}$ wide bleed area in the interaction region. The bleed area consisted of discrete bleed holes drilled normal to the surface. The individual holes, which were $3.17 \mathrm{~mm}$ in diameter, were staggered in alternate rows. The bleed region consisted of 31 rows of holes that could be either left open or filled to vary the extent or location of the bleed region. The geometrical arrangement of the bleed holes is shown in Figure 2. In this study bleed region lengths of 2.5 and $5.0 \mathrm{~cm}$ in the streamwise direction were used.

Instrumentation

Surface oil flow visualization techniques were used to obtain qualitative information about the flow in the interaction region. A thin coat of high viscosity clear motor oil mixed with a fluorescent dye was applied before the tunnel was started. After several minutes of running on condition, the tunnel was shut down rapidly. The resulting pattern was photographed using illumination from an ultra-violet source. This technique suppresses reflections from the metal tunnel surfaces. By monitoring the oil flow patterns with a video camera during a run, it was determined that the combination of 
high viscosity oil and fast shutdown resulted in no change in the oil flow patterns during tunnel shut down.

Surface pressure measurements were obtained from surface taps. The taps

in the bleed region were installed in a separate removable section. The sep-

arate wall pressure measurement allowe, the bleed flow measurements in the bleed plenum to be taken without interference. To provide sufficient surface area around the pressure tap, a bleed hole was sacrificed and the pressure tap was located in its place. The taps were staggered from the centerline to prevent a series of pressure taps occurring along any one line in the direction of flow. Additional surface pressure taps were provided off the centerline tu check for any transverse variation in surface pressure. The wall temperatures were obtained with surface thermocouples.

Boundary layer surveys were made using a pitot pressure probe. The pitotprobe had a flattened $t$ ip with an orifice of $.38 \mathrm{~mm}$. The motion of the probe through the boundary layer and axially along the tunnel was provided with an actuator located downstream of the test section. The motion of the probe was controlled by computer. The pitot probe itseif was electrically isolated $f$ om the tunnel and connected to a touch control. This control provided an indication when the probe contacted the tunnel wall. All boundary layer survey points were referenced to the wall location to eliminate any deflection errors in the probe-actuator system. The accuracy of the touch control was checked under flow conditions optically using a cathitometer. The accuracy was well within the $.025 \mathrm{~mm}$ resolution of the actuator.

The total bleed mass flow rate was measured in the bleed exhaust system with an orifice meter. The local jleed rate was measured using hot wire anemometers as mass flux probes. These probes were located in the bleed plenum. The hot wire probes were mounted on an actuator that could traverse the bleed region in the direction of flow. A schematic of this system is shown in Figure 3 . This technique was selected since the hot wire probes respond to the product PV directly and the small physical dimensions of the hot wire would not interfere with the bleed flow. The mass flow for each row of bleed holes across the flow was determined from the measurement of a typical bleed hole. The total mass flow for each bleed hole measured was determined from a number of readings taken across tile hole in the direction of the flow. This reading was applied to an area segment that extended across the hole and the total flow determined by the summation of these segments. That is, the variation in mass flux across a hole in the direction of flow was measured, but the mass flux normal to the streamwise direction was assumed uniform. The geometrical relationship of the bleed hole, hot wire probe and area segment used in the bleed measurement is shown in Figure 4 . The hot wire probes were calibrated using a device that produced a controlled profile so a mass flux vs. output could be determined. The calibration was zero shifted slightly for each run such that the integrated mass flow from the hot wire measurements would correspond to the independent measurement of the total mass flow made in the bleed exhaust system.

\section{RESULTS AND DISCUSSION}

Qualitative Results

The first prerequisite of any two-dimensional experimental program is to determine the extent of the two-dimensional flow. In this study the twodimensionality was checked by using surface oil flow visualization, surface 
pressure distributions, and local bleed mass flow variations. Initially surface oil flow visualization was used to study the shock-boundary layer interaction without bleed. The no-bleed test could be considered a worst-case study. That is, if the flow could be shown to be primarily two-dimensional for the no-bleed case, the addition of bleed should increase the extent of two-dimensionality. The results of this oil flow visualization are shown in Figure 5. For this case the bleed holes were filled and the bleed plate rotated so the bleed region was positioned upstream of the interaction. This allowed the results in the interaction region to be viewed without the interference of reflections from the material in the filled holes. The results for the shock generator at, $6^{\circ}$ show that, with the exception of very close to the boundary layer fences, the shock interaction region was straight and normal to the flow. An examination of the oil traces upstream and downstream as well as the fine grain structure of the oil in the interaction region indicated no cross flow tendencies. The test was repeated with the addition of bleed. other than a thinning of the indicated interaction region, these results were the same as for the no-flow case.

As stated previously, the variation in bleed rate was measured through the interaction region. To show the effect of the supersonic flow on the mass flux through the individual bleed holes, a comparison between the mass flux distribution for a no-flow and Mach 2.5 case is shown in Figure 6. For the no-flow case the vacuum boost pump was used to provide the pressure difference across the bleed plate. The difference between the two cases is apparent. In contrast to the no-flow case, which has symmetrical mass flux distribution, the supersonic flow case mass flux is skewed to the downstream direction of the bleed hole. The local bleed rates in this study are presented as a function of bleed hole row, where the mass flow rate for the row is determined from a typical hole of the given row. Therefore, the distortion in the direction of flow is accounted for in the integration of the mass flu across the hole.

Quantitative Results

The results presented in the study represent a sample from a larger array of test conditions investigated. The test conditions and definition of symbols are given in Table 1 and 2 respectively. The boundary layer thickness of the initial profile is used to normalize the distance from the wall surface for all profiles for the appropriate Mach number. The length parameter $\bar{X}$ is the distance downstream from the initial profile normalized by the initial boundary layer thickness. Therefore, this value represents the number of initial boundary layer thicknesses downstream of the initial profile. The shock generator angles given are the actual angles with no boundary layer corrections for effective angles.

The initial or farthest upstream pitot pressure profiles ? or Mach 2.0 and Mach 2.5 are shown in Figure 7. Also shown on the figure are pitot pressure profiles for a $1 / 7$ power velocity boundary layer profile. The comparisons show the initial profiles to be slightly fuller than the $1 / 7$ power profile.

A no-bleed case is shown in Figure 8 so that a comparison may be made with subsequent results of interactions with bleed present. The test conditions were Mach 2.5 and shock generator angle of $6^{\circ}$. The bleed holes were plugged for this case. This presents a different boundary condition than leaving the bleed holes open and closing the bleed system. In the latter 
case, recirculation can occur from downstream of the shock interaction, through the bleed plenum, and blown into the lower pressure flow upstream of the interaction. The profile at $\bar{X}=3.20$ and subsequent profiles show $a$ separation is present with the flow beginning to reattach at the final downstream profile. The discontinuity in some profiles show the intersections with the incident and reflected shock waves. The wall pressure distribution is also shown in this figure. This distribution shows an extended interaction region but without the "kink" in the distribution sometimes associated with the turbulent separated interaction.

In concrast, the results in Figure 9 show the shock-boundary layer interaction at the same conditions as those in Figure 8 but with the addition of boundary layer bleed starting at $X=2.86$ and extending for $5.0 \mathrm{~cm}$. For this case the variation in boundary layer bleed rate is also presented. The obvious effect of the bleed as shown by the profiles is the elimination of the separation in the interaction region and the improvement in the fuliness of the profiles. The wall pressure also shows the effect of the bleed. The interaction region is less extensive. The change in slope of the pressure is associated with the high bleed rates occurring in the dow stream portion of the bleed region. This variation in bleed is also shown in the figure. In general, the bleed rate follows the wall pressure distribution. That is, low bleed rate in the low pressure region upstream of the shock and increasing rates through the interaction region.

In Figure 10 the shock generator angle has been increased to $6.5^{\circ}$ with other conditions unchanged. Again the boundary layer profiles show the flow to be attached and the wall pressure distribution is similar to the previous case. However, the bleed rate variation indicates a significant reduction in the upstream bleed. This results from an increase in downstream bleed and a corresponding increase in the bleed plenum pressure. The higher plenum pressure prevents large bleed rates upstream of the shock. Additional increase of the shock strength for this bleed arrangement could completely cut off the upstream bleed or result in local blowing into the boundary layer. Since the hot wire probes used in this study could not resolve flow direction, the measurements could not differentiate between bleeding or blowing. Therefore, greater shock strengths for this bleed arrangement could not be investigated.

The next case, which is shown in Figure 11, is for the same coriditions as the previous case but with $2.5 \mathrm{~cm}$ of bleed starting at $Z=2.86$. The boundary layer profiles again show the flow is attached. The wall pressure distribution for this case does not show the change in slope seen for the $5.0 \mathrm{~cm}$ bleed case. However, for this case the majority of the bleed region is located upstream of the interaction region. The effect of this upstream bleed on the wall pressure is seen by the decrease of the wall pressure immediately upstream of the interaction. This effect can be thought of as turning of the flow because of a decrease in the boundary layer displacement thickness caused by the bleed. Similar wall pressure distributions were observed from $5.0 \mathrm{~cm}$ bleed regions, where the bleed was primarily upstream. The plot of bleed rate shows a fairly uniform bleed rate over most of the region with an increase in the last bleed row. This result of uniform bleed in regions of uniform wall pressure was observed throughout the investigation. This implies that local bleed is substantially independent of the upstream bleed history and that bleed modeling techniques Dased on local flow conditions could be effective. The final case, shown in Figure 12, is an example of the shock-boundary layer interaction at Mach 2.0 with $5.0 \mathrm{~cm}$ of bleed starting at $X=2.93$. The results here substantially follow that presented for $M=2.5$. The boundary layer profiles show attached flow with the exception of profile at $\bar{X}=2.87$ 
that indicates a small separation. The outer portion of that profile and the next indicate a compression wave probably associated with the small separation extending upstream. The wall pressure again has the leveling out followed by a sudden increase at the end of the bleed region. The bleed flow, which for this case is primarily downstream, is fairly uniform over the bleed region.

\section{CONCLUDING REMARKS}

The study of the two-dimensional shock-boundary layer interaction with bleed showed the effect of the bleed preventing separation in the interaction region. The effect of the bleed on the wall pressure distribution is to decrease the wall pressure for bleed upstream of the interaction region or to decrease the slope of the pressure rise for bleed in the interaction region. The local bleed rate is primarily a function of the local flow conditions, which should facilitate the development of bleed models for analytical techniques.

\section{REFERENCES}

1. Lachmann, G. V., Boundary Layer and Flow Control, Pergamon Press LTD, London, 1961.

2. Hakkinen, R. J., Greber, I., Trilling, L. and Abarbanel, S. S., "The Interaction of an Oblique Shock Wave with a Laminar Boundary Layer," NASA Memo. 2-18-59w, Mar. 1959.

3. Settles, G. S., Vas, I. E., and Bogdonoff, S. M.; "Details of a ShockSeparated Turbulent Boundary Layer at a Compression Corner, "AIAA Journal, Vol. 14, No. 12, Dec. 1976, pp. 1709-1715.

4. Rose, W. C., Page, R. J., and Childs, M. E., "Incipient Separation Pressure Rise for a Mach 3.8 Turbulent Boundary Layer," AIAA Journal, Vol. 11, No. 5, May 1973, pp. 761-763.

5. Seebaugh, W. R. and Childs, M. E., "Conical Shock-Wave Turbulent Boundary Layer Interaction Including Suction Effects," Journal of Aircraft, Vol. 7, No. 4, July-Aug. 1970, pp. 334-340.

6. Fukuda, M. K., Hingst, W. R., and Reshotko, E., "Bleed Effects on Shock/ Boundary-Layer Interactions in Supersonic Mixed Compression Inlets," Journal of A ircraft, Vol. 14, No. 2, Feb. 1977, pp. 151-156. 


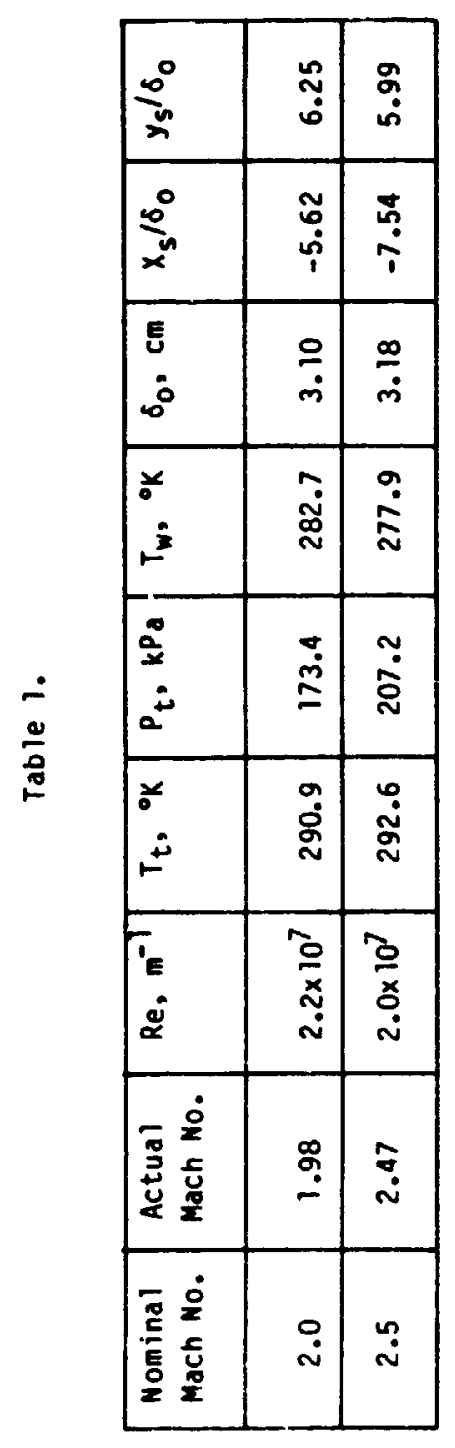

\begin{tabular}{|c|c|c|c|c|c|c|}
\hline \multirow{10}{*}{ 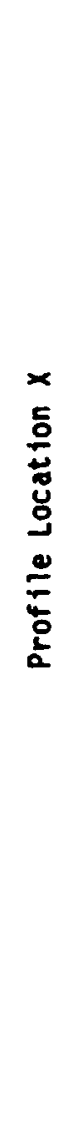 } & \multicolumn{6}{|r|}{ 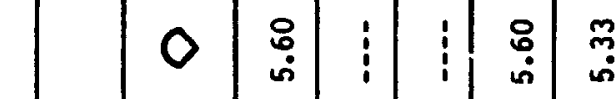 } \\
\hline & 0 & $\stackrel{\varnothing}{\square}$ & 足 & 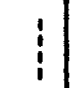 & $\underset{\square}{\stackrel{\Xi}{+}}$ & $\overline{5}$ \\
\hline & $\Delta$ & $\stackrel{9}{9}$ & $\underset{q}{\not}$ & $\vdots$ & $\stackrel{q}{q}$ & $\frac{9}{\ddagger}$ \\
\hline & 0 & $\underset{+}{8}$ & $\frac{9}{4}$ & $\begin{array}{l}0 \\
0 \\
\vdots \\
0\end{array}$ & $\underset{+}{+}$ & $\stackrel{\circ}{\circ}$ \\
\hline & $\Delta$ & $\stackrel{\circ}{\circ}$ & 8 & $\begin{array}{l}0 \\
\vdots \\
\vdots\end{array}$ & $\stackrel{\circ}{\circ}$ & 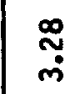 \\
\hline & $D$ & $\underset{\text { లె }}{ }$ & 胥 & \begin{tabular}{l}
8 \\
\hdashline
\end{tabular} & $\underset{్ ల}{~}$ & $\stackrel{\bar{\alpha}}{\sim}$ \\
\hline & $\diamond$ & $\underset{\sim}{\mathscr{Q}}$ & 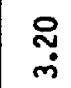 & $\begin{array}{l}0 \\
\vdots \\
\dot{m}\end{array}$ & $\underset{\sim}{\stackrel{\sim}{*}}$ & $\underset{\sim}{2}$ \\
\hline & $\triangleleft$ & $\underset{\dot{\sim}}{\stackrel{P}{2}}$ & $\underset{i}{9}$ & 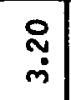 & $\underset{\sim}{q}$ & 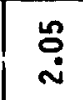 \\
\hline & $\square$ & $\stackrel{\circ}{\circ}$ & $\stackrel{\circ}{\circ}$ & $\stackrel{\circ}{:}$ & $\stackrel{8}{\circ}$ & $\stackrel{\cong}{\cong}$ \\
\hline & 0 & $\stackrel{\circ}{\circ}$ & $\stackrel{8}{8}$ & \begin{tabular}{l}
0 \\
\hdashline \\
\hdashline
\end{tabular} & $\underset{0}{8}$ & @ \\
\hline & & $\stackrel{\circ}{\circ}$ & ì & 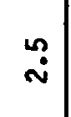 & $\stackrel{\circ}{\circ}$ & is \\
\hline$\stackrel{ \pm}{a}$ & & $\stackrel{\circ}{\circ}$ & 葋 & $\begin{array}{l}0 \\
0 \\
0 \\
0\end{array}$ & $\begin{array}{l}\tilde{8} \\
0\end{array}$ & $\bar{\Xi}$ \\
\hline$\dot{x}$ & & $\stackrel{\circ}{\circ}$ & $\begin{array}{l}\text { mat } \\
\text { g. }\end{array}$ & $\begin{array}{l}\hat{\tilde{a}} \\
0\end{array}$ & dे & $\mid \begin{array}{l}0 \\
\text { d }\end{array}$ \\
\hline$\dot{\phi}$ & & $\stackrel{\circ}{\circ}$ & $?$ & 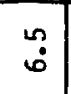 & : & 罟 \\
\hline $\mathbf{x}$ & & $\stackrel{\sim}{\sim}$ & $\stackrel{\sim}{\sim}$ & $\stackrel{n}{\sim}$ & $\stackrel{\sim}{\sim}$ & $\stackrel{i}{i}$ \\
\hline
\end{tabular}


ORIGINAL F̈́

OF POOR QUALit'

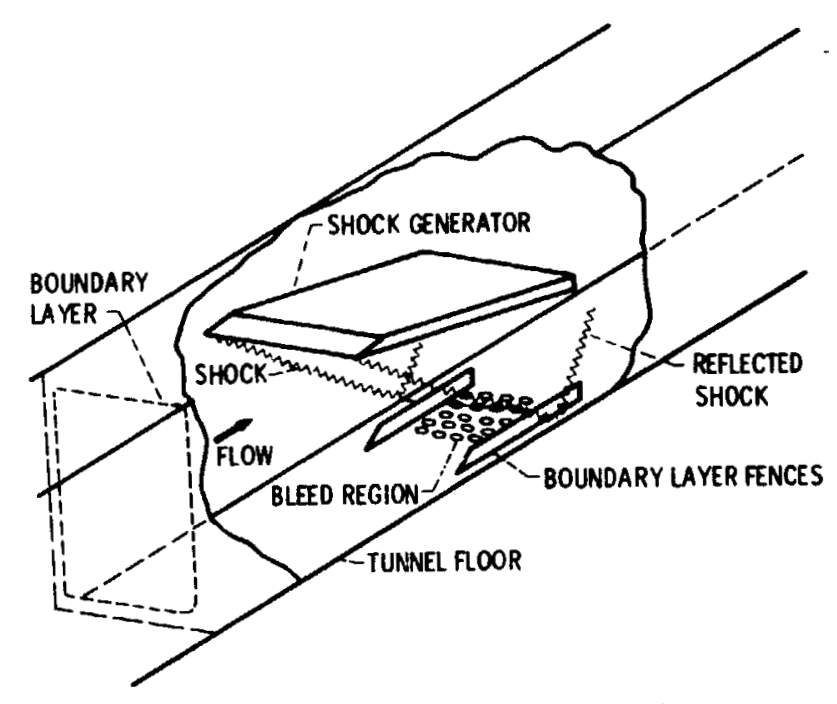

Figure 1. - Schematic of experimental configuration.

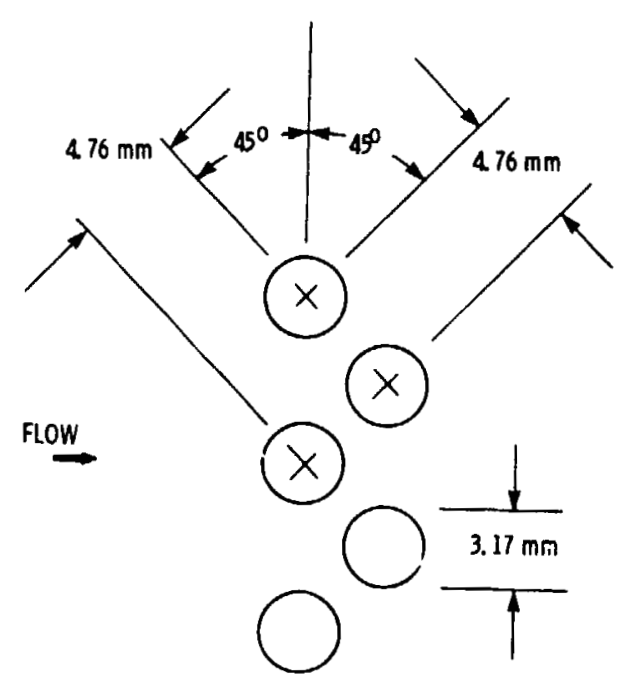

Figure 2. Ceometrical arrangement of bleed holes. 
ORIGINAL PAGE IS:

OF POOR QUALITY

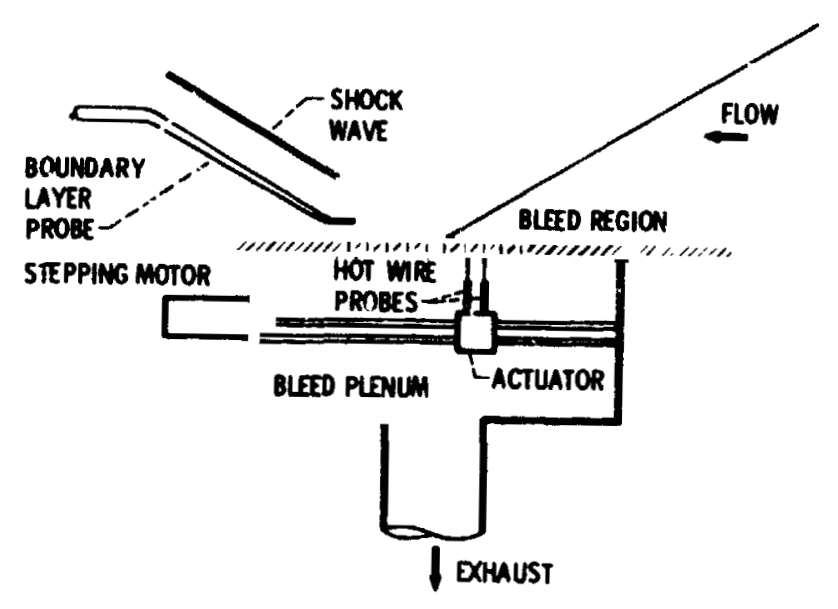

Figure 3 - Schematic of neasurement wchniques.

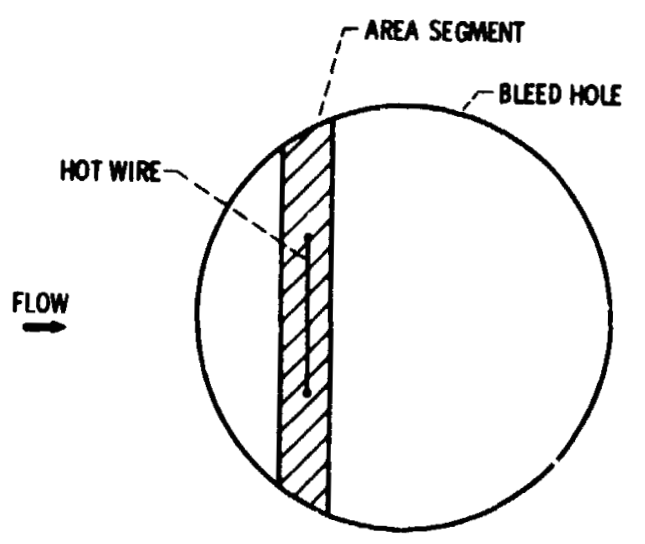

Flgure 4 - Geometical relationshlp of hot wire with bleod hole. 
Onice: :

OF POCR \&

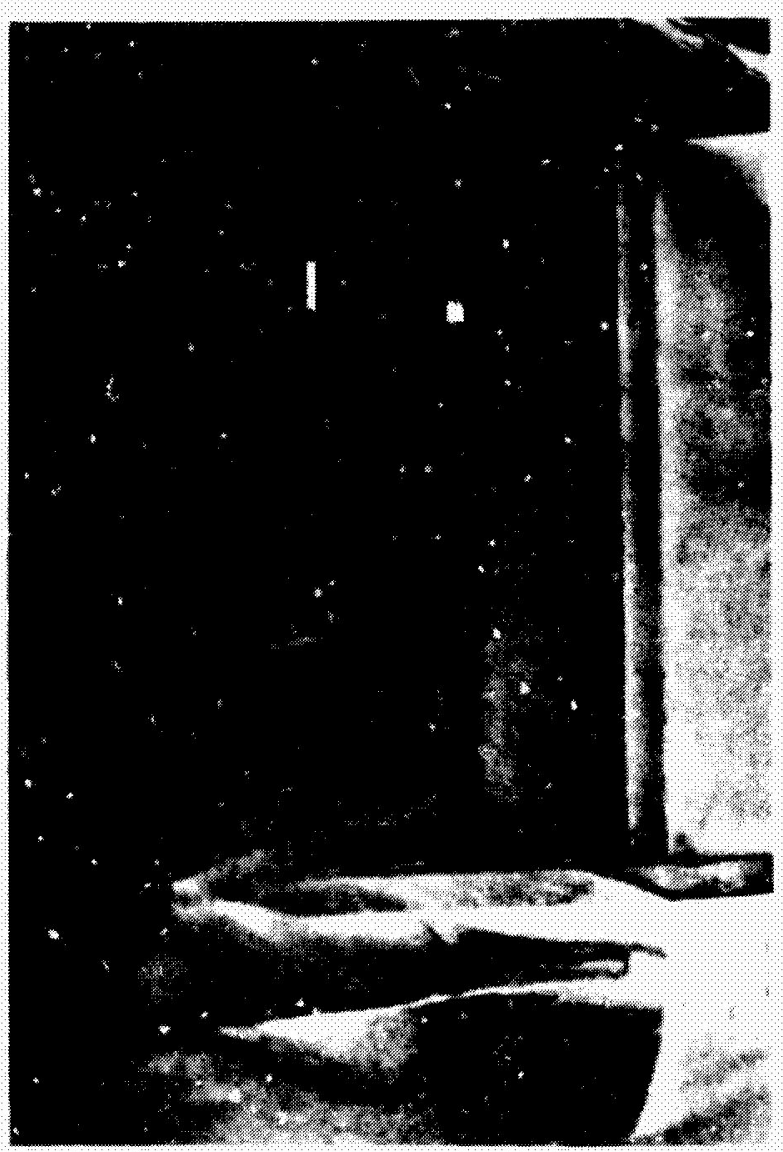

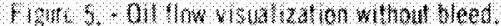

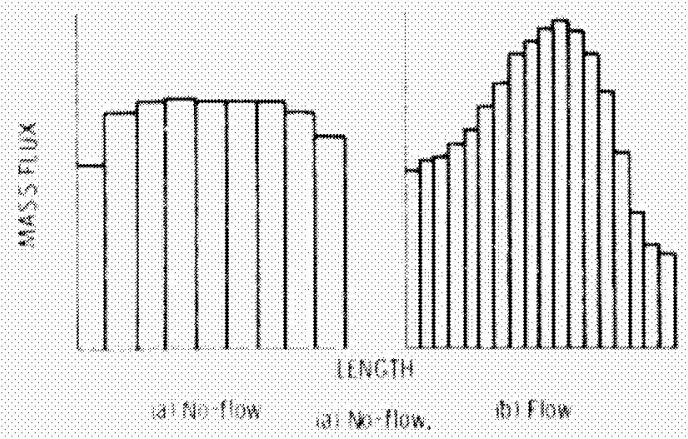

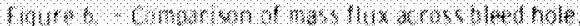


ORIGINAL PAQE I:

OF POOR QUALITY

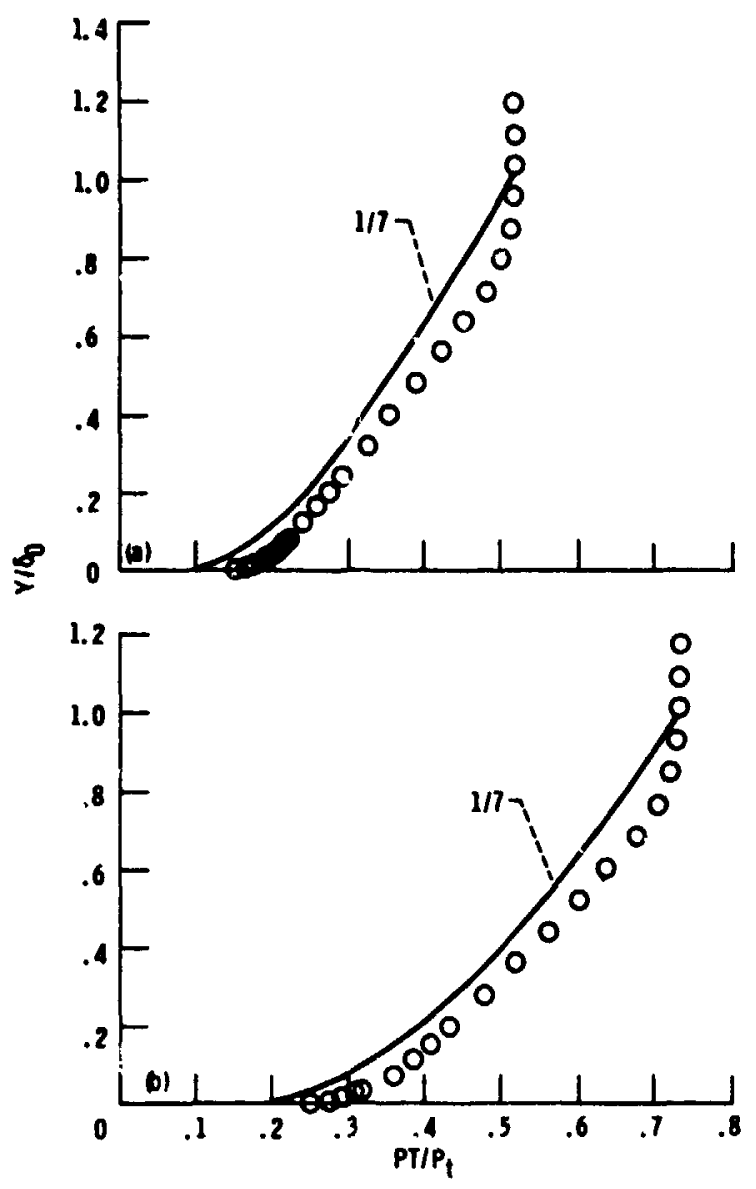

(1) Much 2.0.

b) Muxch 2.5 .

Flgure 7. - Initial phtot pressure profiles compered with velocity power profiles. 
ORIGINAL PACE IO

OF POOR QUALITY
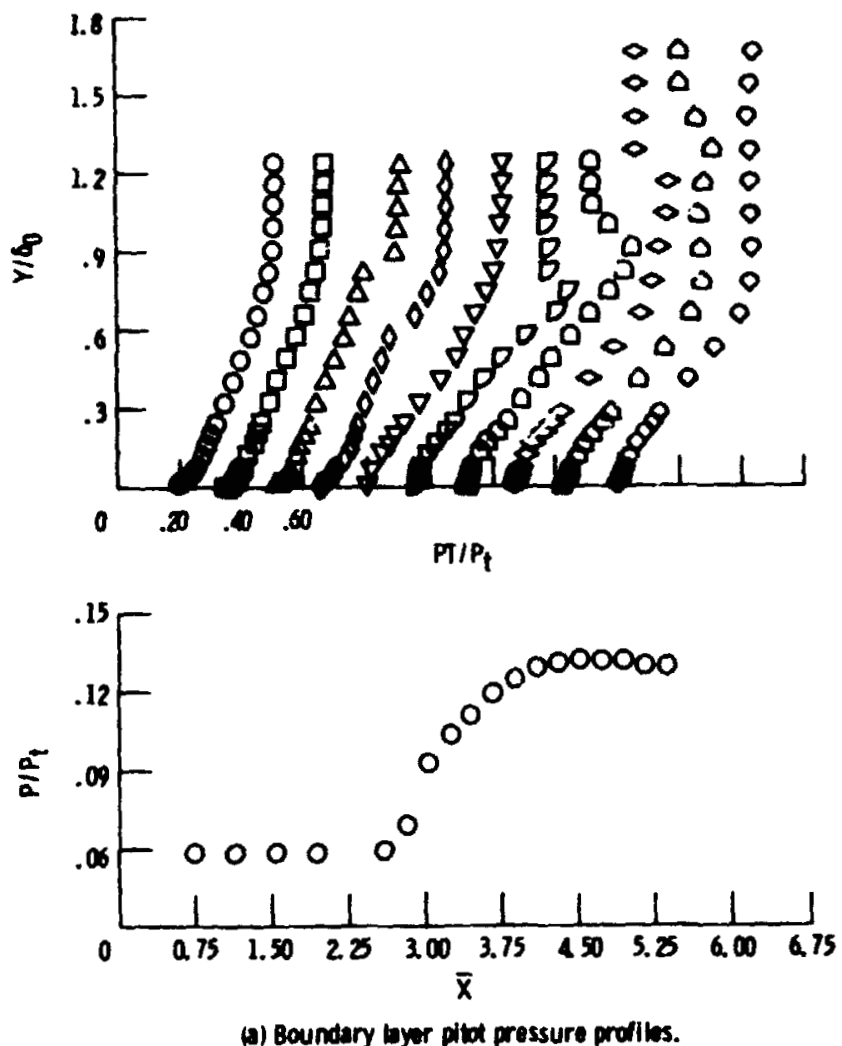

(b) Wall pressure distrbution.

Figure \& - Measurements through interaction for Mach 2.5.

$\theta \cdot 6^{\circ}$ and no blead. 


\section{ORIGINAL PAGE IS \\ OF POOR QUALITY}
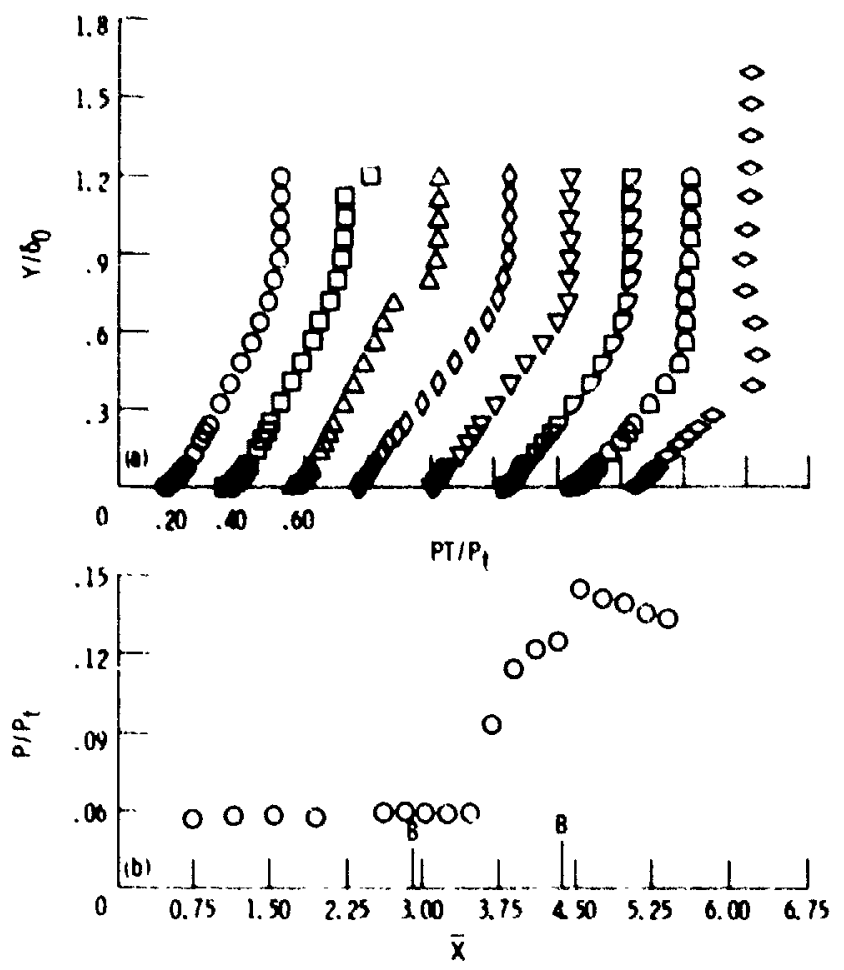

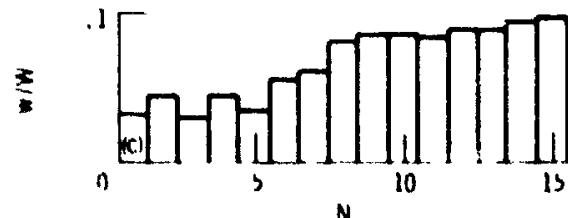

(a) Boundary laver pitol pressure proflies.

(b) Wall pressure distribution.

(c) Bloed llow rate distribution.

Figure $y$. - Measurements through ineraction for Mech 2.5 $\theta \cdot \hat{\theta}$ and $5.0 \mathrm{~cm}$ bleed reglon. 
ORIGINAL F! PI:-

OF POOR QUALITY
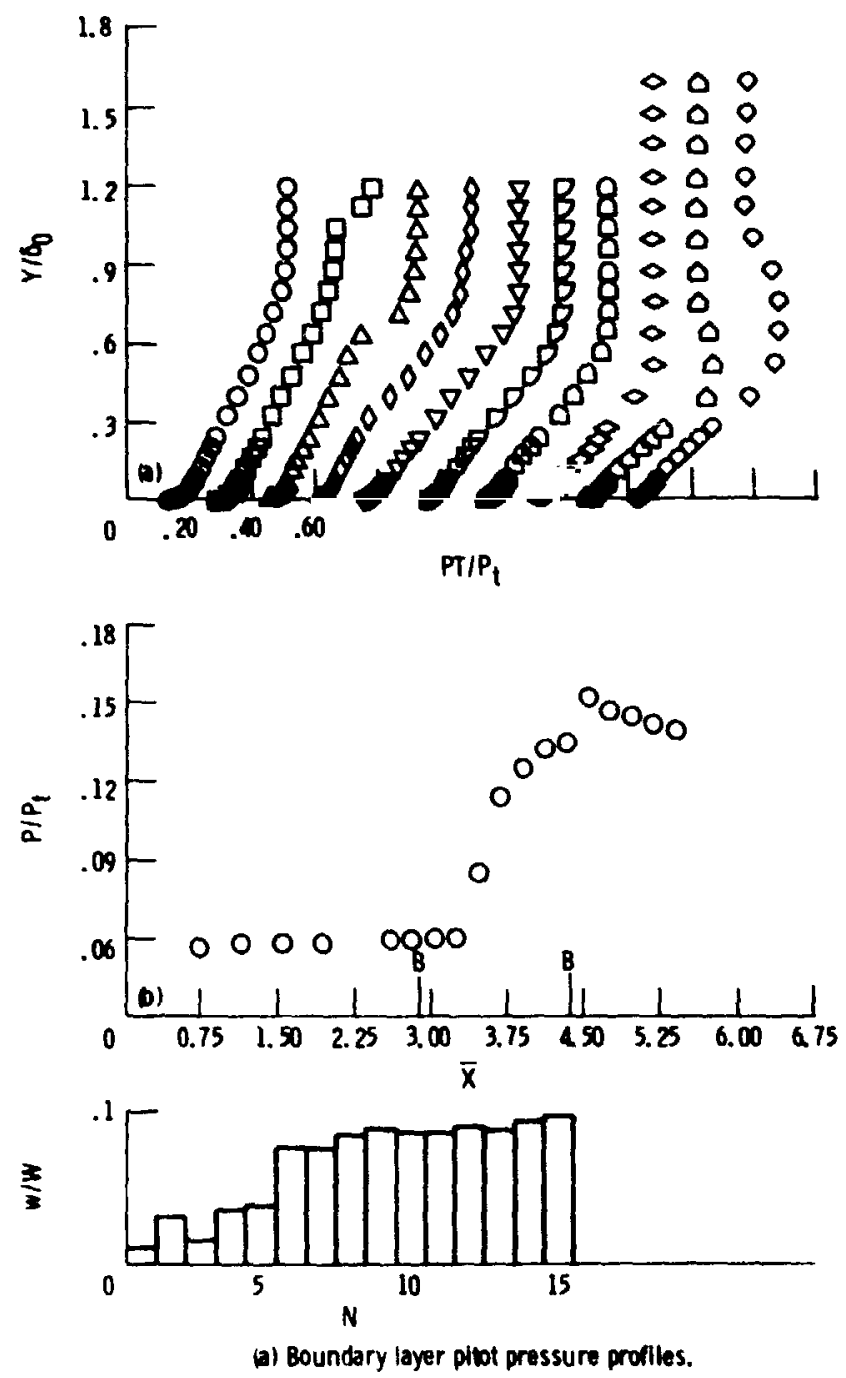

(D) Wall pressure distribution.

(c) Bleed flow rate distribution.

Figure 10. - Masuraments through interaction for Mach 2.5 , $\theta=6.5$ and $5.0 \mathrm{~cm}$ of bleod. 


\section{ORIGINAL PAGE IS}

OF POOR QUALITY
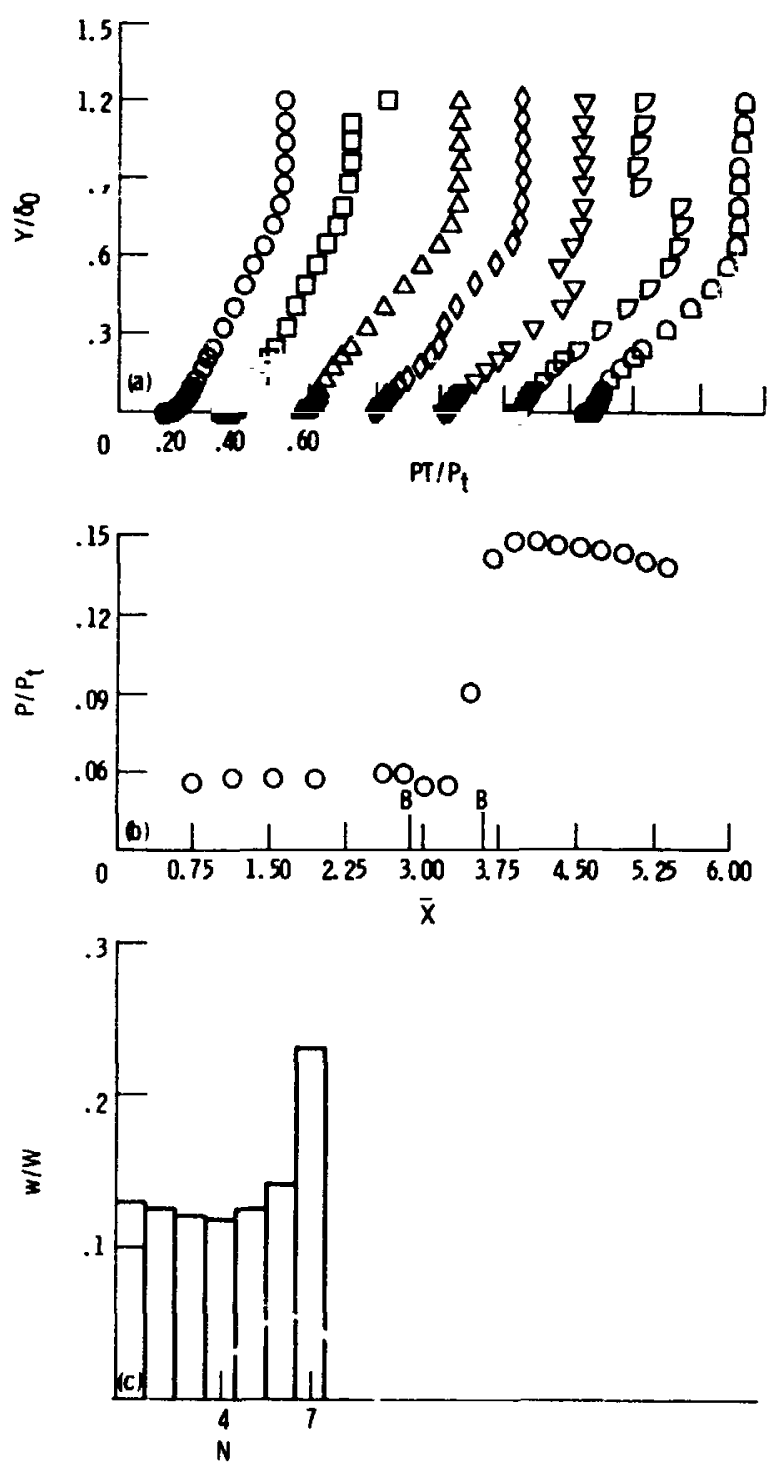

(a) Boundary layer pitot pressu ? profiles.

b) Wall pressure aistribution.

(c) Bleed flow rate distribution.

Figure 11. - Measurements through interaction for Mach 2.5.

$\theta \cdot 6.5^{\circ}$ and $2.5 \mathrm{~cm}$ of bleed. 
ORIGINAL PAGE IS

OF POOR QUALITY
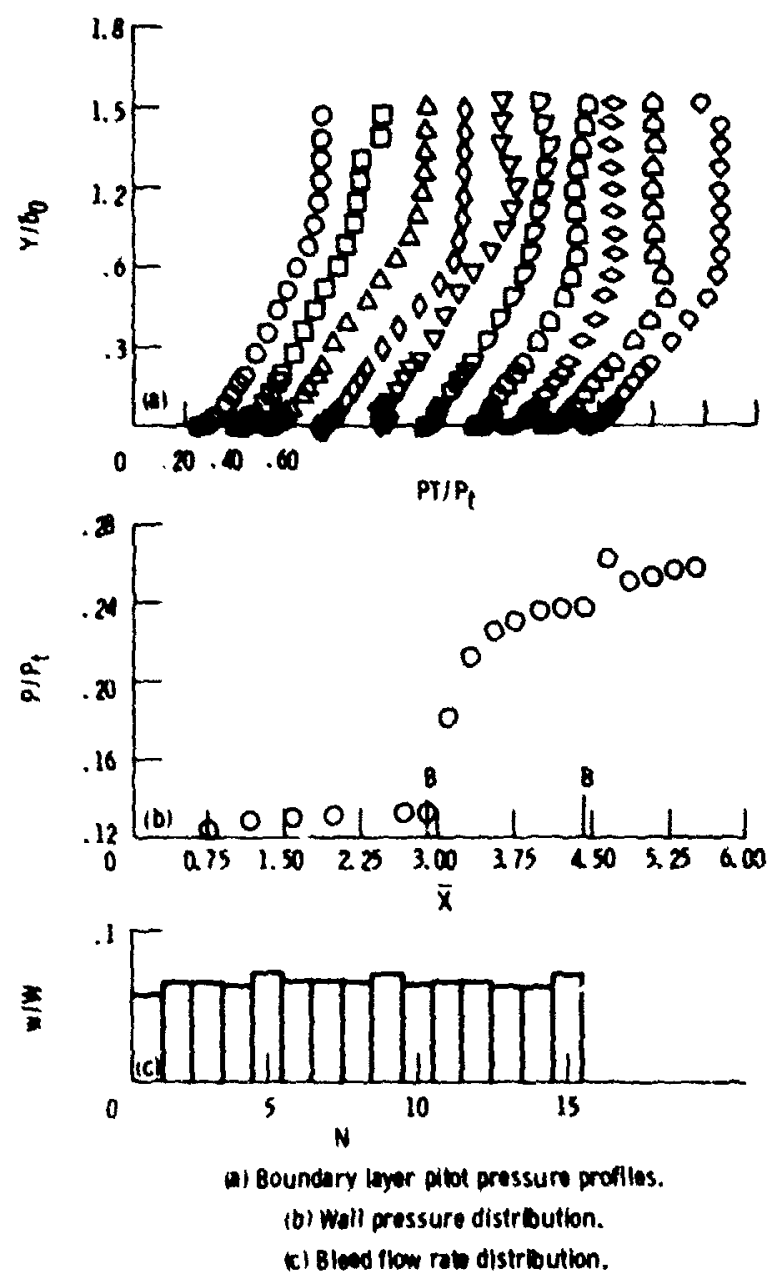

Figure 12 - Masusurements through in wrection for Mach 2.0. $\theta$ - $5 ., 90$ and $5.0 \mathrm{~cm}$ blead. 